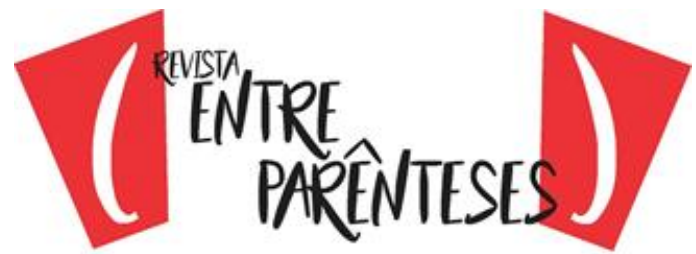

\section{LEXICOGRAFIA DISCURSIVA NA SALA DE AULA: ANÁLISE DE 'HOMOSSEXUAL' EM DICIONÁRIOS DISTINTOS}

\author{
Breno Oliveira CORREIA ${ }^{1}$ \\ Universidade Federal de Alfenas - UNIFAL-MG - MG \\ (brennocontabilidade@gmail.com)
}

\begin{abstract}
Resumo: Este artigo tem como objetivo promover uma discussão a respeito do uso de dicionários na sala de aula como um instrumento didático. Para isso, serão consultadas edições contemporâneas. Por fim, analisaremos uma palavra específica para demonstrar os sentidos atribuídos a ela de acordo com cada um dos cincos dicionários selecionados, demonstrando as semelhanças e diferenças entre as definições.
\end{abstract}

Palavras-chave: dicionários; sala de aula; sentidos.

Abstract: This article has the objective promotes a discussion about the use of dictionaries in the classroom as a didactic instrument. For that, contemporary editions will be consulted. Finally, it will be analysed a specific word to demonstrate which its meaning in accordance to five selected dictionaries, demonstrating the similarities and difference between the meanings.

Keywords: dictionaries; classroom; meaning.

Resumen: Este artículo busca promover el debate con relación a la utilización de diccionarios en clase como herramienta didáctica. Por lo tanto, se consultará ediciones actuales. Al final, analizaremos una palabra específica para demostrar el significado a ella atribuido según los cinco diccionarios seleccionados, demostrando las semejanzas y diferencias entre las definiciones.

Palabras-clave: diccionarios, clase, significado.

\section{INTRODUÇÃO}

O que é um dicionário? Segundo a definição do Dicionário Houaiss da Língua Portuguesa, é uma "listagem, geralmente em ordem alfabética, das palavras e expressões de uma língua ou um assunto com seus respectivos significados ou sua equivalência em outro idioma" (HOUAISS, 2009). Segundo a definição do Aulete digital, dicionário é obra que reúne, em ordem alfabética, as palavras de uma língua ou termos referentes a uma matéria específica, e descreve seu significado, uso, etimologia etc., na mesma língua ou em outra (dicionário de cinema / de inglês). É o conjunto das palavras ou termos reunidos nessa obra. Um dicionário qualifica-se como um livro de referência em que se fornecem informações, com a categoria gramatical,

\footnotetext{
1 Graduado em Letras - Licenciatura em Português pela Universidade Federal de Alfenas (2018).
} Professor da rede pública de educação do Estado de Minas Gerais. 


\section{("Wîtrer}

as acepções, os registros, a forma correspondente noutros idiomas, sobre palavras e expressões de uma língua, apresentando-as de acordo com uma ordem convencional, geralmente alfabética. Eles podem ser classificados em várias categorias: dicionários bilíngues, dicionários monolíngues, dicionários enciclopédicos, dicionários analógicos, dicionários multilíngues etc.

O dicionário é uma ferramenta muito utilizada no contexto escolar/acadêmico. Está presente em diversas atividades propostas pelos professores, principalmente os de língua materna. Fazendo uso constante desse material, o aluno promove o aprimoramento e a expansão do vocabulário, a escrita correta das palavras (ortografia), entre outros benefícios. Mesmo com toda sua praticidade, os professores devem estar atentos ao propor atividades que usufruem dos desse recurso acadêmico, pois, por mais que não aparenta, eles são carregados de valores ideológicos. Sendo assim, através deste trabalho, demonstraremos como uma mesma palavra assume significados distintos em dicionários contemporâneos diferentes e como as definições variam, mesmo se trantando de um mesmo vocábulo. Também, é fundamental ressaltar a importância do professor como mediador no processo de ensino/aprendizagem, direcionando a prática dos alunos e sendo criterioso na escolha de quais materiais levar para a sala de aula.

\section{USO DO DICIONÁRIO NA SALA DE AULA}

O dicionário é um recurso muito utilizado pelas editoras, jornais, gráficas, escolas, professores de língua materna em suas aulas etc. Porém, mesmo sendo usado de forma categórica, os dicionários são poucos explorados nos diversos contextos nos quais eles poderiam ser de grande utilidade, favorecendo práticas de uso eficientes e eficazes. O uso dessa ferramenta também faz-se muito pertinente nas aulas das demais disciplinas, como física, biologia, história. Nas aulas de língua estrangeira (inglês, espanhol) fazemos o uso dos dicionários bilíngues, com fins específicos para a tradução das palavras da língua estrangeira para a língua materna e vice-versa. 


\section{("tither}

No contexto atual, o uso dos dicionários faz-se muito pertinente, por exemplo, nos estabelecimentos de ensino de educação básica, abrangendo ensino fundamental e ensino médio.

A adoção de um dicionário como um dos instrumentos didáticos básicos do ensino de língua justifica-se porque esse tipo de obra oferece, de forma sistematizada, informações sobre o léxico, seus usos e sentidos, bem como pode trazer informações de natureza histórica e gramatical dos ítens lexicais e demais elementos. Em virtude do conjunto das informações que encerra, o dicionário constitui-se em lugar privilegiado de lições sobre a língua (KRIEGER, 2003).

Todos os alunos deveriam conhecer as possibilidades que thes oferece essa ferramenta de consulta. É um instrumento imprescindível para a aprendizagem do léxico e da língua em geral. Deveria estar presente em todas as aulas de língua materna e demais disciplinas da grade escolar. Os próprios documentos que regem a educação brasileira, como o PNLD Dicionários (BRASIL, 2002), demonstram a importância do uso de dicionários nas aulas de língua materna e das demais disciplinas.

Diferente de outros gêneros, o dicionário tem um forte compromisso com o léxico de uma língua, pois ele é "uma reconstrução teórica do mundo das palavras, a partir de experiências concretas sempre limitadas" (RANGEL, 2006, p. 15). É uma fonte de consulta sobre palavras, expressões e sentidos desconhecidos.

Na escola, a importância do dicionário vem ganhando espaço à medida que aumenta a preocupação com o ensino do léxico. De acordo com Biderman (1996) o léxico de qualquer língua é a somatória de toda a experiência acumulada de uma sociedade e do acervo da sua cultura ao longo do tempo.

Para Richards (1976) ensinar léxico, isto é, permitir ao aluno o conhecimento das palavras e do vocabulário, implica expandir o vocabulário ao longo da vida; conhecer a frequência e a colocação das palavras; conhecer as limitações de uso impostas às palavras; reconhecer o comportamento sintático das palavras; compreender formas subjacentes e derivacionais (regras de formação) das palavras; saber estabelecer associações entre as palavras numa relação intralinguística; conhecer o valor semântico das palavras, seus traços e suas restrições semânticas 


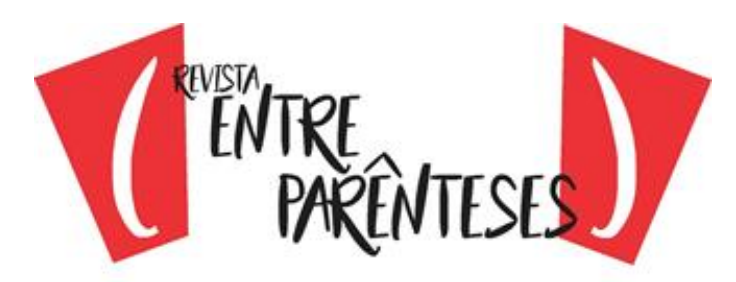

de uso; e conhecer as várias possibilidades de uso das palavras por meio da sua multissignificação.

Contudo, um dos grandes problemas é que os alunos não estão adaptados a fazer o uso dessa ferramenta. Pontes e Santiago (2009) afirmam que o aluno se frustra diante do dicionário por não ter sido "treinado" para usá-lo adequadamente. Essa situação justifica-se principalmente pelo fato do professor não se formar bem teórica e metodologicamente para o trabalho com o dicionário em sala de aula (p.105).

A respeito do dicionário como ferramenta, temos:

Dentre todos os livros que compõem nossas bibliotecas, alguns deles se destacam dos demais por serem livros de consultas, e não livros que costumamos ler do princípio ao fim. São os dicionários, enciclopédias, guias de viagens, listas telefônicas, páginas amarelas, livros de culinária, etc. (VIEIRA et al., 2008, p. 35).

É notório que os dicionários têm um caráter distinto da concepção que temos sobre livros. É diferente dos livros didáticos, dos livros de literatura (romances, contos, novelas), dos livros de ficção científica, etc. É um livro usado para fins específicos e determinados, ou seja, em geral, para a consulta de significados possíveis e análise de léxico. Mas, além de auxiliar nas pesquisas, ele pode ser mais útil do que se pensa, pois, o ser humano lê além do que procuramos. Sendo assim, ele deve ser visto como um livro de leitura e não como uma mera listagem de palavras e seus respectivos significados. O dicionário precisa ser visto a partir de uma perspectiva diferente das tradicionais. Necessita ser melhor explorado. Ele é uma ferramenta vastíssima de pesquisas e leitura que possibilita o debate sobre a língua, sobre as definições das palavras, sobre o posicionamento do dicionarista ou lexicógrafo, questões que o professor deve levar para a sala de aula e levantar questionamentos para que os alunos reflitam sobre eles, como já apontado na introdução.

\section{LEXICOGRAFIA DISCURSIVA}




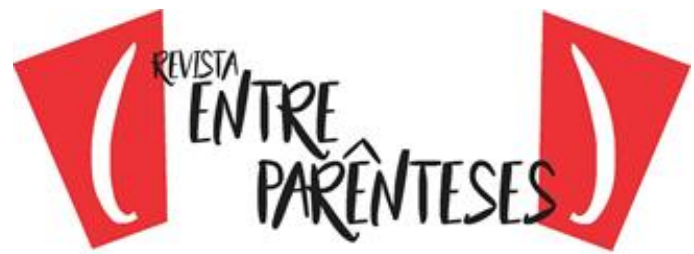

Além de mostrar a importância do dicionário na sala de aula, devemos lembrar que os dicionários, assim como qualquer outro texto, constituem-se discursos produzidos em certas condições, tendo o seu processo de produção vinculado a uma determinada rede de memória que se fez por meio da língua (ORLANDI, 2000).

De acordo com Orlandi (2000), se temos o dicionário como instrumento linguístico, produzido na história, em um certo momento, devemos perceber também que, ao perder seu caráter monumental para ser objeto tangível de nossa relação com a língua na história, ele se apresenta como vestígio de nossa memória histórica, social e cultural.

Considerando a obra lexicográfica como material histórico e que essa obra foi construída por alguém ou por um grupo de pessoas, na figura de seu autor, ela individualiza o saber sobre a língua de uma sociedade na história.

É nessa relação entre o texto, seu autor e a memória cultural como reflexo do saber compartilhado que influencia a escrita desse texto que a lexicografia discursiva se mantém.

Essa perspectiva defende que não há palavra, não há sentido, sem ideologia, já que, segundo a análise de discurso, fala-se a mesma língua, mas fala-se diferente. Para Orlandi (200) isso é silenciado pelo próprio dicionário: Não se olha o dicionário a partir de como os sentidos das palavras estão em processo, ou de como elas se distribuem, significando diferentemente, de acordo com as diferentes formações discursivas, que correspondem a diferentes posições do sujeito ante a ideologia (2000, p. 101).

Pensando nisso, procuramos compreender o funcionamento do dicionário em uma sociedade como a nossa, pensando como os fatos fazem sentido. Para isso, apresentaremos uma pequena análise do verbete 'homossexual' e observamos os efeitos da discursividade em cinco dicionários de língua.

\section{ANÁLISE DE DADOS}

Professores, principalmente os de língua materna, fazem o uso do dicionário em sala a fim de auxiliar nas atividades desenvolvidas com os seus alunos. 


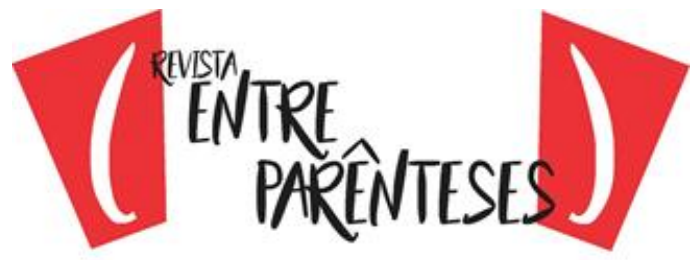

Diante disso, vamos analisar os sentidos que a palavra 'homossexual' assume em cinco diferentes dicionários. Assim, os alunos poderão contribuir de forma significativa nas discussões entorno das definições das palavras, demonstrando as diferenças, atentando para os detalhes que cada dicionário traz, analisando qual definição é mais abrangente, quais definições seriam mais ideais, entre outras.

No dicionário Houaiss, a palavra 'homossexual' significa: 1 relativo a homossexualidade <pessoa com tendências h.> 2 mantido por indivíduos do mesmo sexo (diz-se de relacionamento sexual) $\mathbf{3}$ que denota homossexualidade (comportamento h.). 4 que ou aquele que sente atração sexual e/ou mantém relação amorosa e/ou sexual com indivíduo do mesmo sexo.

Ao ver a definição desse dicionário, notamos que o sentindo mais abrangente, ou seja, aquele mais conhecido entre as pessoas (o sentido popular, costumeiro), está apenas na quarta e última definição do vocábulo. Lembrando que se trata de uma edição recente, do século XXI (2009). Por ser uma edição bem atual, no cenário onde o movimento LGBT já conquistou muitos avanços em meio à sociedade, esperava-se um conceito mais atual, que melhor define a palavra, ou seja, um conceito mais democrático. Mas não é isso que realmente acontece. As definições perpetuadas por séculos ainda são exploradas, demonstrando que as diferenças sociais estão imbuídas em concepções ideológicas até na construção de um dicionário.

No dicionário Aulete digital, as definições para a palavra 'homossexual' são: 1 ref. a homossexualidade (relação homossexual). 2 que sente atração por e/ou tem relações sexuais com pessoas do mesmo sexo. Esse dicionário é mais econômico, pois usa apenas duas definições para 'homossexual'.

A primeira acepção não é clara, pois remete a outra palavra da mesma família que, dependendo da idade do aluno, ele não saberá o significado de nenhuma das duas. A definição mais conhecida só é explorada na segunda e última definição. Por se tratar de uma ferramenta online, esperava-se uma definição mais objetiva e comum na primeira acepção.

No dicionário Michaelis digital, os significados para a palavra "homossexual" são: 1 relativo a homossexualidade. 2 diz-se de relacionamento sexual 


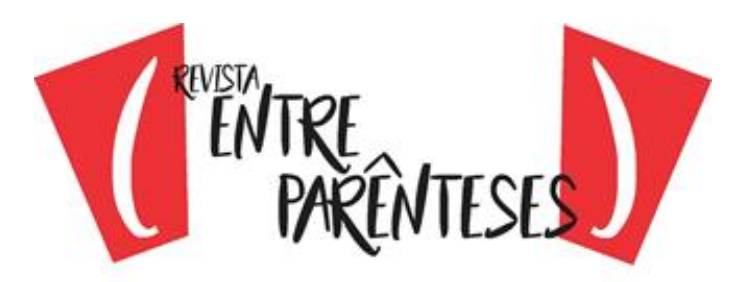

entre indivíduos do mesmo sexo. $3(\operatorname{adj} m+f s m+f)$ que ou aquele que tem atração sexual por indivíduos do mesmo sexo; entendido, gay, guei, invertido, uranista.

O dicionário Michaelis digital também não usa a definição mais comum na primeira acepção. Como o dicionário Aulete, ele apresenta a acepção costumeira partir da segunda definição. É interessante notar que, na terceira definição, faz-se o uso da palavra "gay", que é a forma mais tradicional que as pessoas usam para se referir a um homossexual.

No dicionário Aurélio, as definições para a palavra 'homossexual' são as seguintes: 1 diz-se da relação sexual ou afetiva mantida entre pessoas do mesmo sexo. 2 que ou quem sente atração sexual por pessoas do mesmo sexo ou tem relações sexuais ou afetivas com pessoas do mesmo sexo. 3 o mesmo que homossexual.

O dicionário Aurélio se diferencia dos demais no que tange às definições. Desde a primeira acepção, ele define o sentindo mais costumeiro que a palavra assume, que é a pessoa que mantém relações sexuais com outra do mesmo sexo biológico.

O Dicionário Online da Língua Portuguesa (Dicio) traz as seguintes definições para a palavra homossexual: 1 que se refere a homossexualidade: relacionamento homossexual. 2 refere-se aos que se sentem atraídos (sexualmente e/ou emocionalmente) por pessoas do mesmo sexo. 3 que pratica relações sexuais com pessoas do mesmo sexo. 4 que demonstra homossexualidade: discurso homossexual.

O Dicionário Online da Língua Portuguesa (Dicio), como a maioria, define apenas o sentido popular a partir da segunda acepção. Além do mais, diz que a palavra é o contrário de heterossexual. É uma questão muito complexa, pois daria uma bela discussão a respeito de gêneros.

No geral, todos os dicionários trazem definições bem simplificadas. Apresentam, aproximadamente, três definições para cada palavra. Apenas o dicionário Houaiss traz uma definição mais detalhada se comparado aos demais. Mesmo assim, nenhum dos dicionários analisados traz a definição mais conhecida como sendo a primeira, exceto o Aurélio, que apresenta já no início a definição mais 


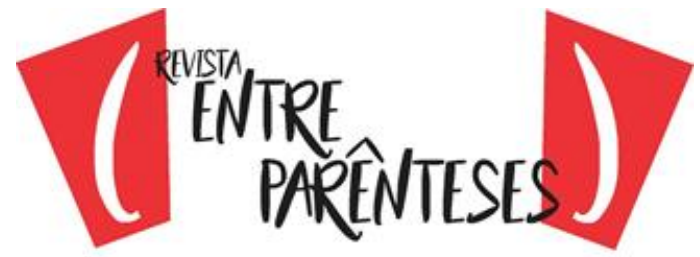

comum da palavra. No geral, as pessoas sabem que "homossexual" é a pessoa que gosta de outra pessoa do mesmo sexo, ou seja, que mantém relações amorosas/sexuais com alguém que possui o mesmo sexo biológico que o seu. Essa definição mais comum, popular entre as pessoas, só apareceu a partir da segunda definição nos outros quatro dicionários pesquisados.

Nos cinco dicionários, exceto no Aurélio, a primeira definição para a palavra é "que está relacionado a homossexualidade". É outro problema que o professor pode encontrar caso não faça uma análise criteriosa antes de levar o material para a sala de aula. Os alunos vão questionar o motivo. Muitos não saberão o que é a palavra homossexualidade, principalmente se for crianças.

No dicionário Michaelis digital, na terceira definição, é usada a palavra "invertido" para definir "homossexual". De acordo com o Google, "invertido" significa: virado em sentido contrário, oposto ao que é natural ou ao que se encontrava anteriormente. Essa definição usada pelo dicionário Michaelis digital é muito problemática, pois quando diz que é oposto ao que é natural, está dizendo que é algo não-natural. Isso causaria um grande problema ao professor se o aluno questionasse o porquê que não é natural a pessoa escolher com quem se relacionar. Questões como essa, demonstram como os dicionários são carregados de cargas ideológicas, sendo muitas vezes até preconceituosos e discriminatórios.

\section{CONSIDERAÇÕES FINAIS}

Sabemos que nenhum falante conhece por completo o léxico da sua língua. É notório também que nunca conseguiremos fazer uso de todo esse léxico disponível. Com isso, ressalta-se a importância dos dicionários para qualquer comunidade linguística e a sua necessidade de fazer parte das aulas de língua materna.

Portanto, com base na análise da palavra 'homossexual', a partir de diferentes perspectivas possíveis, vemos como é problemático trabalhar com o uso do dicionário em sala de aula. O professor deve estar atento às abordagens que utilizará na aplicação das atividades didáticas e deixar os alunos sempre cientes da carga ideológica que contém cada um. 


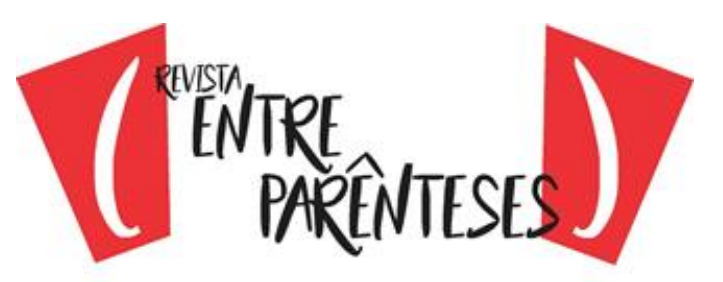

Cada um dos dicionários traz definições diferentes, umas mais abrangentes, outras mais simplificadas, outras mais tendenciosas, dos vocábulos. É necessário estar atendo a cada detalhe, a fim de evitar sérios problemas no processo de ensino/aprendizagem.

Vivemos num país diversificado. A sala de aula é um universo muito heterogêneo, portanto, o professor precisa fazer a escolha de materiais adequados ao contexto regional e cultural, priorizando sempre a concepção de ensino mais democrática e correta possível.

\section{DICIONÁRIOS CONSULTADOS}

HOUAISS, Antônio. Dicionário Houaiss da Língua Portuguesa. Rio de Janeiro, Ed. Objetiva Ltda., 2009.

http://www.aulete.com.br/. Acesso em 03 de agosto de 2018.

http://www.michaelis.com.br/. Acesso em 03 de agosto de 2018.

https://www.dicio.com.br/. Acesso em 04 de agosto de 2018.

FERREIRA, Aurélio Buarque de Holanda. Mini Aurélio: o dicionário da língua portuguesa. 8. ed. Curitiba: Positivo, 2010. 895 p. ISBN 978-85-385-4240-7

FERREIRA, Aurélio Buarque de Holanda. Dicionário da língua portuguesa. 5. ed. Curitiba: Positivo, 2010. 2222 p. ISBN 978-85-385-4198-1.

\section{REFERÊNCIAS}

BIDERMAN, M. T. C. Léxico e vocabulário fundamental. Alfa, v.40, p. 27-46, 1996.

BRASIL. Resolução/CD/FNDE no 055 de 14 de dezembro de 2004. Dispõe sobre a aquisição de dicionários brasileiros da Língua Portuguesa para o Programa Nacional do Livro Didático - PNLD. Diário Oficial da União. Seção 1. p. 98. Brasília, DF, 15 dez 2004.

KRIEGER, M. G. Dicionário de língua: um instrumento didático pouco explorado. In: TOLDO, C.S. (Org.). Questões de Linguística. Passo Fundo: UPF Editora, 2003. p. 70-87. 
ORLANDI, E. P. Lexicografia discursiva. Alfa, São Paulo, v. 44, p. 97-114, 2000.

PONTES, A. L.; SANTIAGO, M. S. Crenças de professores sobre o papel do dicionário no ensino de língua portuguesa. In: COSTA DOS SANTOS, F. J. (Org.). Letras plurais: crenças e metodologias do ensino de línguas. 1 ed. Rio de Janeiro: CBJE, 2009 , v., p. $105-123$.

RANGEL, E. O. Dicionários em sala de aula / elaboração Egon de Oliveira Rangel, Marcos Bagno. Brasília: Ministério da Educação, Secretaria de Educação Básica, 2006. $155 \mathrm{p}$.

RICHARDS, J. The role of vocabulary teaching. TESOL Quarterly v. 10, n. 1, 1976.

VIEIRA, Adriana Silene; FERNANDES, Célia Regina Delácio; SILVA, Márcia Cabral da; MARTINS, Milena Ribeiro. Organização e uso da biblioteca escolar e das salas de leitura. Fascículo 4. In: BRASÍLIA. Ministério da Educação Básica. Secretaria de Educação Básica. Pró-letramento: programa de formação continuada de professores dos anos iniciais/séries iniciais do ensino fundamental: alfabetização e linguagem. Brasília: MEC, 2008.

Recebido em 20/10/2018.

Aceito em 04/02/2019. 